\title{
Regulation and Opportunism: How Much Activism Do We Need? ${ }^{1}$
}

\author{
Aleix Calveras $^{2} \quad$ Juan-José Ganuza ${ }^{3} \quad$ Gerard Llobet ${ }^{4}$
}

This Draft: September, 2005

\footnotetext{
${ }^{1}$ We thank Guillermo Caruana and Humberto Llavador for helpful comments. Juan-José Ganuza acknowledges the hospitality of CEMFI and the financial support of the Spanish Ministry of Science and Technology under project SEC2003-08080-C02-01. The usual disclaimer applies.

${ }^{2}$ Department of Business Economics, Universitat de les Illes Balears. Cra Valldemossa Km 707122 Palma de Mallorca, Spain. E-mail: aleix.calveras@uib.es.

${ }^{3}$ Department of Economics, Universitat Pompeu Fabra. C/ Ramon Trias Fargas 25-27 08005 Barcelona, Spain. E-mail: juanjo.ganuza@econ.upf .es.

${ }^{4}$ CEMFI. C/ Casado del Alisal 528014 Spain. E-mail:1lobet@cemfi.es.
} 


\begin{abstract}
This paper analyzes the current trend towards firms' self-regulation as opposed to the formal regulation of a negative externality. Firms respond to increasing activism in the market (conscious consumers that take into account the external effects of their purchase) by providing more socially responsible goods. However, because regulation is the outcome of a political process, an increase in activism might imply an inefficiently higher externality level. This may happen when a majority of non-activist consumers collectively free-ride on conscious consumers. By determining a softer than optimal regulation, they benefit from the behavior of firms, yet they have access to cheaper (although less efficient) goods.
\end{abstract}

JEL Codes: D72, H42, L51, M14, Q52

Keywords: Activism, Corporate Social Responsability, Voting and Regulation. 


\section{Introduction}

Traditionally, market failures have been addressed using formal regulation. For instance, firms that produce goods that generate environmental externalities have been subject to pollution taxes, quotas and standards. Recently, however, these public politics have been complemented with private politics. ${ }^{1}$ The rise of activism by consumers/citizens and the phenomenon of corporate social responsability (CSR) have thus changed the way economics regard the control of externalities. ${ }^{2}$ To the extent that some conscious consumers (which we call activists) take into account in their purchasing decisions the social behavior of the firm, a firm may go beyond strict profit maximization by choosing more expensive production technologies that reduce its externalities.

As Baron (2003) puts it, the choice between public and private politics is strategic. This is precisely the aim of our paper; to study whether private and public politics are really substitutes or not, and the overall result of this interaction over social welfare. We study this interaction in the context of the build-up of a negative externality (e.g. pollution) as a by-product of the consumers' purchasing decision. Our results show that if private politics are controlled by activist consumers, but public politics are in the hands of non-activist voters, a free-riding equilibrium can arise. The reason is that non-activists benefit from a loose regulation. This regulation (or lack of it) allows non-activists to buy cheap goods at the expense of a higher aggregate externality, and hence they shift the burden of the reduction of externality to the conscious purchasing decisions of activists. As a result, a society with consumers heterogeneous in their degree of activism might suffer from a higher externality than a more homogeneous (even if less conscious overall) society which would rely mainly on formal regulation. In other words, more activism may imply, in some cases, that self-regulation inefficiently crowds out formal regulation.

At the heart of our analysis is the activism of consumers. By activism we denote the extent to

\footnotetext{
${ }^{1}$ According to Baron (2003) "The term private means that the parties do not rely on public order, i.e. lawmaking [...]. The term politics refers to individual and collective action [...]"

${ }^{2}$ See, for instance, Carroll (1979) and McWilliams and Siegel (2001) on the corporate social responsibility of the firm from a managerial perspective.
} 
which an agent internalizes the externalities generated by his consumption when deciding which product to purchase. Generally, the direct impact on any given consumer of the externality generated by his or her own consumption is negligible. Thus, absent the so-called activism, we should expect every consumer to free-ride and ignore such external effects at the time of purchase. Evidence indicates, however, that for some consumers there exists a willingness to pay a higher price for products of firms that adopt some practices labeled as socially responsible or, alternatively, to penalize those firms that are perceived to be socially irresponsible (see, for instance, Mohr et al. (2001) and Murray and Volgel (1997)). ${ }^{3}$ These conscious consumers take into account (to a varying degree) the externalities generated by their decisions despite the negligible consequence that they may have on their own welfare. Thus, such activists might be willing to pay higher prices for goods that are produced without harming the environment, that are produced by firms that employ handicapped workers, or that do not involve child labor. ${ }^{4}$

Activism feeds back on the policies and strategies adopted by firms. Absent any regulation, in a society with a large number of activist consumers, it is in the interest of firms to adopt socially responsible practices. Intuitively, the degree and the amount of activism in any given society should have a positive impact on the behavior of firms since it will lead them to adopt the socially responsible practices and strategies that activist consumers value at the time of their purchase. Hence, private politics by a larger amount of activists should imply a higher reduction in the equilibrium externality. As Bargnoli and Watts (2003) show, firm competition in this context might result in an inefficiently low level of externality. Instead, here we assume a perfectly competitive supply of goods with heterogeneous technologies and we ignore the strategic behavior of firms. We thus abstract from the debate regarding the motivation and implications of CSR, studied in papers such as Baron (2001) and Innes (2005).

\footnotetext{
${ }^{3}$ Other important issues around activism are the availability of information, the formation of organizations/lobbies among consumers, and the launching of boycotts by activists. Since in many instances the negative externalities generated by firm activity are not directly observed by consumers, their degree of potential activism is also restricted by the existence of organizations that are capable of providing such information. Feddersen and Gilligan (2001) address this issue by assuming that the output of the firm is a credence good and the role of an active organization is to provide information about its behavior. Baron (2001) discusses the effect of the possibilities of a boycott on a firm's strategy. We abstract from these issues by assuming perfect information regarding the behavior of the firm, and taking activism without explicitly modelling boycotts.

${ }^{4}$ Feddersen and Gilligan (2001) provide additional illustrations related, for example, to oil companies.
} 
Our analysis then draws attention to the effect of activism on public politics. Regulation is often enacted either directly through the voting of particular decisions, like the California environmental initiatives studied by Kahn and Matsusaka (1997), or indirectly through political elections. The model we present shows that the effect of the level of activism among consumers in the degree of regulation resulting from the political process is not necessarily monotonic. In other words, more activism may imply more or less stringent endogenous regulation. The intuition goes as follows. Initially, consumers/citizens decide collectively by means of majority voting (which in our setup is simply the choice of the median voter) the level of regulation (e.g. they may restrict the available type of technologies that firms are allowed to choose), taking into account the aggregate result of their actions. To simplify the discussion, suppose for the moment that there are only two type of consumers: activists, that completely internalize the externality, and non-activists that do not care at all about the externality at the time of purchase. Our results show that a society with very few activists will choose to regulate very strictly (e.g. allow firms to produce only with the cleaner and socially efficient technology) since market oriented incentives through the willingness to pay of conscious consumers do not operate. This result arises from the fact that the non-activist median voter can use regulation to limit the inefficient private behavior of other non-activists. Similarly, a society with a majority of activists will also choose a very strict regulation to reduce free-riding of the non-activist minority.

However, a society with a majority of non-activists, but a significant proportion of activist consumers, may choose to regulate less strictly than socially optimal. In such a case, some firms, responding to the demand of non-activists, might choose socially inefficient technologies. Why, then, the majority of non-activists may choose to regulate too little? Because, on the one hand, non-activists know that the significant amount of activists will consume socially efficient products and thus reduce substantially the level of overall externality. And, on the other hand, non-activists will be able to consume cheaper products with a lower marginal cost of production but a higher social cost. Thus, in a sense, non-activists consumers choose to collectively free-ride on activists. 
This is the main message of our paper, and we view it as throwing caution against the present trend towards the request of socially responsible behavior of firms, rather than a precise regulation of their activity. It may very well be true that activism (conscious consumption) has increased in present societies; however, this trend does not guarantee that CSR is a good substitute of full-fledged regulation.

Our analysis lies within the literature dealing with the political economy of environmental regulations. Part of this literature focuses on the process whereby policymakers make their decisions over environmental regulations, discussing issues such as, for instance, the capture of the regulator by some specials interest group. ${ }^{5}$ Some other recent papers have recently incorporated the endogenization of environmental regulation. Their emphasis is on sociodemographic variables, such as income, that affect the public support towards environmental regulations both from an empirical point of view (Kahn and Matsusaka (1997) or Elliott et al. (1997)) and from a theoretical one (Marsiliani and Renstrom (2002)). Closer to this latter approach, ours is, to our knowledge, the first work to endogenize the environmental regulation in the presence of activist consumers/voters.

The trade-off between private decisions and public policy has been studied under a different focus in the literature on philanthropy (see Andreoni (2004) for a survey). This strand of the literature studies private contributions (charity) by individuals to a public good. One of their findings is precisely that the public provision of the public good may crowd-out to some extent the private contribution of individual agents. It is argued that because the public provision of the good is funded through distortionary taxation, this crowding out may lead to inefficiencies. Our results point to the opposite direction. The political process that sets the public contribution of the good is affected by the level of activism. The control of the political process by non-activist consumers might allow them to free-ride on the private contribution of activist consumers. Hence, a low level of public contribution might signal an inefficiently low level of provision of the good.

The paper is structured as follows. In section 2, we present the model and we characterize

\footnotetext{
${ }^{5}$ see Ciorcirlan and Yandle (2003) for a short survey of this policymaking strand of the literature.
} 
the market equilibrium for a given regulation. In section 3, we solve the voting game and present the main results of the paper. Section 4 analyzes the robustness of the model to the existence of a cost of enacting a regulation and to adding heterogeneity in the valuation of consumers. We also show that alternative regulatory instruments, such as pollution taxes, lead to similar results. Section 5 concludes. All proofs are relegated to the appendix.

\section{The Model}

Consider a market with only one good that can be produced with different technologies. The quality and characteristics of the good are independent of the technology used. The different technologies are indexed by $x$, which belongs to the $[0,1]$ interval. The technology $x$ implies that the constant marginal cost of production of the good is $c(x)$. Each unit of production also generates $b(x)$ units of externality which is suffered by all consumers, with $b(1)=0$. We assume that $c(x)$ and $b(x)$ are twice-continuously differentiable in $x$, with $c(x)$ increasing in $x$ and $b(x)$ decreasing in $x$, so that technologies that generate a lower externality are associated with a higher marginal cost. ${ }^{6}$ Moreover, the social cost of each unit of production, $c(x)+b(x)$, is decreasing in $x$. Finally, we assume that $c^{\prime \prime}(x) \geq 0$ and $b^{\prime \prime}(x)>0$.

A unit mass of consumers have quasilinear preferences and derive utility $v>0$ from the consumption of a single unit of the good. For the time being we assume that $v$ is sufficiently large so that consumers always buy, and we later study the case where the market is not covered. Consumers are homogeneous in the effect of the aggregate externality but are heterogeneous in how they regard the externality generated from their own decision. This heterogeneity is comprised in a parameter $\theta$ that is distributed according to $F(\theta)$ where $F(0)=0$ and $F(1)=1$. As we will make explicit later, we denote as $B$ the aggregate externality derived from the purchasing decisions of all consumers. As a result, a consumer of type $\theta$ that buys a unit of the good created with technology $x$ derives utility at a price $p(x)$ of

$$
U(\theta, x)=v-p(x)-\theta b(x)-B .
$$

\footnotetext{
${ }^{6}$ This last assumption is obviously without loss of generality, since technologies dominated in terms of $c$ and $b$ would not be used.
} 
Thus, $\theta$ denotes and measures the degree of activism of the consumer: the higher $\theta$ is, the more conscious and activist the consumer is, internalizing to a larger extent the externality generated. ${ }^{7}$

Firms are assumed to be competitive in this market and they face no fixed or entry costs. Consequently, competition will lead all firms producing a good using technology $x$ to set a price equal to marginal cost, $p=c(x)$.

The stages and the timing of the game are as follows. In the first stage, voters decide, according to a majority rule, on a minimal technological standard $\bar{x}$. In the second stage, consumers decide simultaneously which good to purchase and firms produce using technologies with $x \geq \bar{x} .^{8}$ As usual, we solve the game by backward induction.

As it is often the case in environments with externalities, the competitive equilibrium will fail to be efficient. Consumers do not fully internalize the cost that their consumption imposes on others (they only internalize a share $\theta \leq 1$ of their own externality), and therefore they might choose a good produced with an inefficient technology. We start by describing the first best solution, that we use as a benchmark in the rest of the paper.

\subsection{The First Best}

An immediate consequence of the previous technological assumptions, is that the total social cost of production is minimized if all firms choose to produce with technology $x=1$. In other words, social welfare is maximized when only the best technology is used. As an illustration, consider first the case where consumers do not internalize at all the cost of the pollution resulting from their own consumption. That is, $F$ is degenerate around 0 . In this case, all consumers will choose goods produced with the same technology ${ }^{9}$ and social welfare

\footnotetext{
${ }^{7}$ Similar preferences are those in which people experience a "warm-glow" from giving, as in Andreoni (2004). The philanthropy literature (which discusses the private provision of public goods) assumes that individuals actually derive utility from they themselves making a contribution to some public good. Notice this is analogous to the direct disutility (represented by $\theta$ ) that activists experience in our model from purchasing a good that is produced by a polluting technology.

${ }^{8}$ We will refer to agents as voters in the first stage, and as consumers in the second in order to distinguish between the two decisions.

${ }^{9}$ Alternatively ,social welfare maximization could assign to homogeneous consumers different technologies if, for example, the social cost of the externality were concave in the contribution of each individual.
} 
maximization corresponds to the utility maximization of a representative consumer,

$$
\max _{x} v-c(x)-B
$$

where $B=b(x)$. Given the assumptions of the model, this utility is increasing in $x$ in all the 0 to 1 range, and the corner solution describes the optimal outcome, $x^{s}=1$. The next lemma states that this result is general for any distribution function.

Lemma $1 x^{s}=1$ for all $\theta$ and any distribution $F$.

Given the assumptions stated above, from a social standpoint, technologies indexed with a higher $x$ reduce the social cost of production of the good and increase total welfare. This result holds true regardless of the level of activism, or whether society takes into account the private costs that activists incur when buying high externality products or not. As we later see, this simplifying assumption reinforces our results.

\subsection{The Market Equilibrium}

We start by deriving consumer demand in the second stage of the game for a given minimal standard $\bar{x}$. Consumers choose from the set of goods produced with the allowed technologies $[\bar{x}, 1]$ the one that maximizes their utility taking as given the aggregate level of the externality. In other words, a consumer of type $\theta$ chooses $x$ so as to

$$
\max _{x \geq \bar{x}} v-c(x)-\theta b(x) .
$$

As mentioned earlier, consumers only internalize a proportion $\theta$ of the external effect derived from their purchase. The first order condition of this problem implies that the activist's optimal choice of technology $x^{*}(\theta)$ satisfies

$$
\theta=-\frac{c^{\prime}\left(x^{*}\right)}{b^{\prime}\left(x^{*}\right)},
$$

whenever $x^{*} \geq \bar{x}$. Otherwise, the minimum standard is binding and $x^{*}=\bar{x}$. Hence, the optimal choice is defined as

$$
\hat{x}(\theta, \bar{x}) \equiv \max \left\{x^{*}(\theta), \bar{x}\right\} .
$$


It is easy to verify from the assumptions of the model that $x^{*}(\theta)$ is continuous and strictly increasing ${ }^{10}$ in $\theta$ so that, as expected, more conscious consumers choose goods produced with cleaner technologies. A higher standard also implies that consumers choose goods with (weakly) higher $x$. The next simple lemma is a direct consequence of these results.

Lemma 2 A higher standard $\bar{x}$ or a distribution $F^{\prime}$ that first-order stochastically dominates $F$ result in a lower externality level.

This lemma states two clear and intuitive results. First, if the minimal standard $\bar{x}$ is higher, the level of the externality is lower; and, second, if the degree of activism is higher, the externality will also decrease. We next show, however, that this second result does not necessarily translate to the context of majority voting on the minimal standard. The reason is precisely that activism and a higher standard are substitutes in terms of achieving a lower level of externality.

\section{Voting a Standard}

We now turn to the first stage in which consumers vote on the technology with the highest externality allowed, defined by the minimal standard $\bar{x}$. We assume a majority voting system. Then, to begin with, notice that the most preferred standard for a consumer of type $\theta, \bar{x}^{*}(\theta)$, solves

$$
\max _{\bar{x}} v-c(\hat{x}(\theta, \bar{x}))-\theta b(\hat{x}(\theta, \bar{x}))-\int_{0}^{1} b(\hat{x}(s, \bar{x})) d F(s) .
$$

Thus, when considering their preferred minimal standard, consumers do take into account the externalities generated by all consumers together with their own cost. An immediate result from the previous specification is stated in the following lemma.

Lemma $3 \bar{x}^{*}(\theta) \geq x^{*}(\theta)$.

\footnotetext{
${ }^{10}$ To guarantee strict monotonicity we need to introduce the additional assumption that $c^{\prime}(1)=-b^{\prime}(1)$, so that $x^{*}(\theta)=1$ only for $\theta=1$. This assumption is only made for expositional purposes and all the results would follow if $x^{*}(\theta)=1$ for some $\theta<1$. In that case, the distribution of $\theta$ could be redefined to bunch all consumers for which the optimal choice was 1 .
} 
This means that a voter always prefers a standard $\bar{x}^{*}(\theta)$ that precludes, at least, any technology worse than his most preferred choice. The reason is that a lower standard does not affect the technology that the consumer chooses in the last stage but allows technologies that increase the externality of less conscious consumers. Moreover, a voter might be interested in prohibiting technologies beyond his most preferred choice if the decrease in the total externality that this higher standard generates, is higher than his loss in utility from buying a more expensive variety. Therefore, the previous lemma implies that $\hat{x}\left(\theta, \bar{x}^{*}\right)=\bar{x}^{*}$ and the problem of the voter regarding her most preferred minimal standard $\bar{x}(\theta)$ can be rewritten as

$$
\max _{\bar{x}} U(\bar{x}, \theta)
$$

where

$$
U(\bar{x}, \theta) \equiv v-c(\bar{x})-\theta b(\bar{x})-b(\bar{x}) F\left(\theta^{-1}(\bar{x})\right)-\int_{\theta^{-1}(\bar{x})}^{1} b\left(x^{*}(s)\right) d F(s),
$$

and $\theta^{-1}(x)$ is the value $\theta$ for which $x^{*}\left(\theta^{-1}(x)\right)=x$; thus, $x^{*}\left(\theta^{-1}(\bar{x})\right)=\bar{x}$. Notice that by setting a standard, a consumer de facto sets the level of pollution of consumers below $\theta^{-1}(\bar{x})$, and this is the reason why he may only internalize part of the aggregate cost of the externality, not all of it.

The consumer' preferences described by the utility function outlined in the previous paragraph are not necessarily single-picked in the choice of the standard. In fact, the consumer utility function is likely to have multiple local maxima, corresponding to a standard of 1 and other interior values of $\bar{x}$. However, the structure of the problem is such that consumers preferences for a level of a standard can be ordered according to their degree of activism.

Lemma $4 U(\bar{x}, \theta)$ has increasing differences in $\bar{x}$ and $\theta$. Therefore $U$ satisfies the singlecrossing condition.

As a consequence, the complementarity between the standard and the level of activism implies that more activist consumers prefer a higher minimal standard. Hence, a lower (higher) minimal standard is preferred by less (more) activist consumers than the median voter. The 
result of the voting process will be, therefore, defined by the most preferred option of the median voter, denoted as $\tilde{\theta} .{ }^{11}$ The next proposition characterizes the outcome of the voting decision.

Proposition 1 Majority voting determines a standard that is either the socially optimal level $\bar{x}^{*}=1$, or $x^{*}\left(\theta_{1}\right)<1$, where

$$
\theta_{1}=\tilde{\theta}+F\left(\theta_{1}\right)
$$

The previous expression implies that, as stated in the lemma above, the choice of standard of the median voter applies not only to him but also to more activist voters, up to $\theta_{1}$. For this reason, the standard that the median voter chooses has two effects on his welfare. First, it sets the good he consumes, affecting his private utility. Second, it sets the total externality generated by activists of type $\theta$ up to $\theta_{1}$. The sum of the two effects implies that, in the interior solution, we can interpret $\theta_{1}$ as the virtual type of the median voter, so that the minimal standard results from

$$
\max _{x} v-c(x)-\left(\tilde{\theta}+F\left(\theta_{1}\right)\right) b(x) .
$$

This expression shows that, as opposed to the social planner, in an interior solution the median voter internalizes only partially (by an amount $\tilde{\theta}+F\left(\theta_{1}\right)$ ) the increase in social welfare of a higher standard. Moreover, it is easy to see that the lower is $\tilde{\theta}$, the more likely it is that the median voter is inclined to choose a standard that is too low from a social viewpoint.

The resulting standard arises from the comparison between the interior solution (or solutions) and the socially optimal standard corresponding to the most efficient technology, $x^{s}=1$. The low standard implies a lower private cost of consumption and a higher externality. Hence, it is likely to dominate if $\tilde{\theta}$ is low and the distribution of consumers above the median voter is skewed towards a large $\theta$. Conscious consumers would choose a high $x$ even with a low standard and, as a result, the reduction in the externality of increasing the standard from $x^{*}\left(\theta_{1}\right)$ to 1 would be small. In other words, an inefficiently low standard is more likely to arise if the median voter can free-ride on the low externality decisions of highly activist consumers.

\footnotetext{
${ }^{11}$ See Gans and Smart (1996) for a proof and illustrations of the Median Voter Theorem when preferences satisfy the single-crossing condition.
} 
Two cases are particularly good illustration of the previous discussion. Suppose that all voters are non-activists, so that the distribution of $\theta$ is degenerate around 0 . In this case, the interior solution characterized by equation (3) and the socially optimal standard coincide, so that $\theta_{1}=1$. The resulting standard is binding for all consumers and hence, the median voter internalizes all the effects of the externality generated as a planner would do. Similarly, if the median voter is higher than $1 / 2$, then $\theta_{1}>1$ and the optimal standard is also enacted. However, as the next proposition states, for intermediate degrees of activism of the median voter an inefficiently low level of the standard - corresponding to the interior solution - can arise.

Proposition 2 When all consumers are non-activists, the socially optimal standard is the outcome of majority voting. However, a higher degree of activism (i.e, moving from a distribution $F$ to $F^{\prime}$, where $F^{\prime}$ stochastically dominates $F$ ) may imply an increase in the externality level.

The statement of the previous proposition can be generalized in the following sense. When all consumers are identical, regardless of their level of activism the socially optimal standard is chosen. The reason is that the median voter behaves as the "representative consumer" for which a social planner would maximize utility. An increasing dispersion in the distribution of activists - even when consumers become more activist - enhances the payoff of the free-riding effect previously mentioned and may lead to the inefficient level of the standard. This result suggests that the more polarized is the distribution, the more likely is this distortion to occur. The example we provide next studies the most polarized situation and it also serves as a proof the previous proposition.

\subsection{The Binomial Case}

Let $F$ be a two-point distribution for which $\theta=1$ with probability $\alpha$ and $\theta=0$ with probability $1-\alpha$. We simply denote consumers with $\theta=0$ as "non-activist" and those with $\theta=1$ as "activist" consumers. The median voter will be non-activist as long as $\alpha<\frac{1}{2}$. We characterize next the standard chosen by this median voter for different values of $\alpha$, and we represent in Figure 1. 


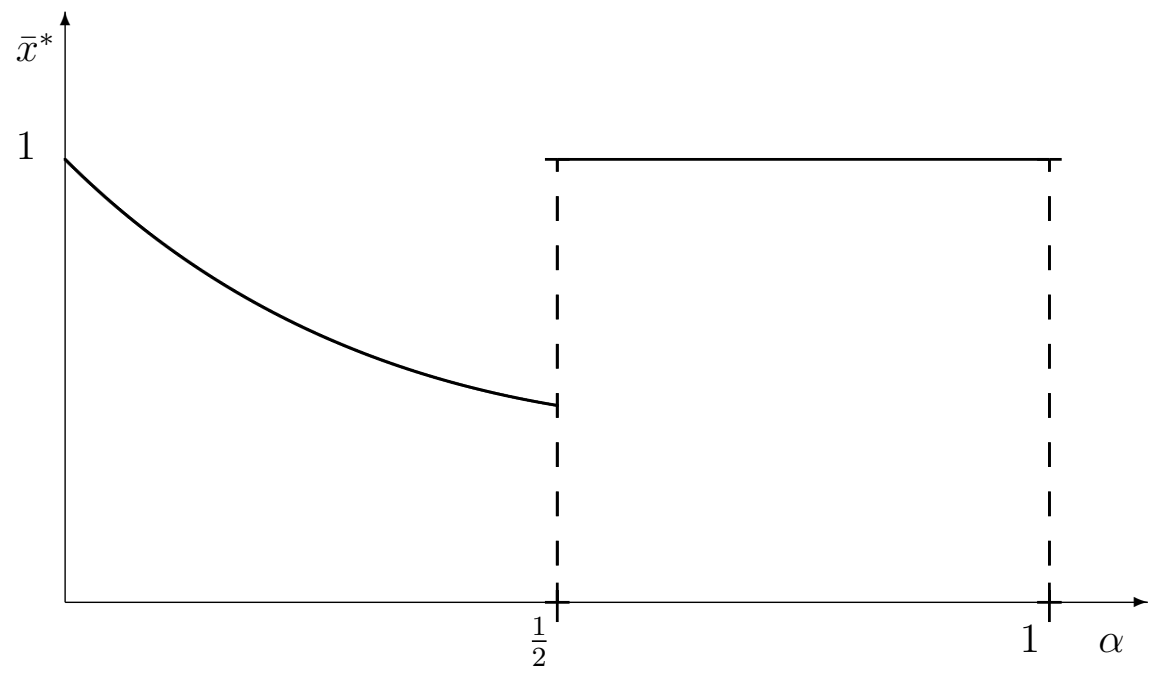

Figure 1: A lower standard is chosen for intermediate levels of activism.

When $\alpha$ is small and the median voter is "non-activist", Proposition 1 states that the optimal standard corresponds either to the corner solution $\bar{x}^{*}(1)=1$ or to an interior solution $\bar{x}^{*}\left(\theta_{1}\right)$, characterized by (3). The interior solution implies a unique virtual type $\theta_{1}=F\left(\theta_{1}\right)=1-\alpha$, the proportion of non-activists in the population.

Notice that the utility of the median voter can be written in this case as $v-c(\bar{x})-(1-$ $\alpha) b(\bar{x})-\alpha 0$. In other words, the ex-ante utility of the median voter corresponds to the ex-post utility of a fictitious consumer with $\theta=1-\alpha$. Given that $\bar{x}^{*}(1-\alpha)$ corresponds to the optimal choice of this virtual consumer, it is immediate that the median voter will prefer an interior standard to the socially optimal technology $x^{s}=1$.

The standard illustrated in Figure 1 also constitutes a proof of Proposition 2. When there are no activists, the level of externality is 0. However, as activism increases the level of the standard is reduced and a positive level of externality arises in equilibrium. Thus, interestingly, for all positive $\alpha<\frac{1}{2}$ there is a crowding out of the formal regulation (minimal standard) by the consumer "activism".

It is important to notice that although the standard decreases with the level of activism, the total externality does not necessarily increase. This result is the sum of two countervailing 
effects corresponding to the extensive and the intensive margin. On the one hand, there are less people that choose the technology that generates the externality. But on the other hand, these consumers will choose an even inferior technology.

Finally, when $\alpha \geq \frac{1}{2}$, the median voter is an "activist" and, according to the previous proposition (given that $\tilde{\theta}=1>\frac{1}{2}$ ), he will choose the socially optimal standard $\bar{x}^{*}(1)=1$. The intuition is simply that at the time of purchase an activist does internalize fully the social cost of pollution and, thus, he does take it into account at the time of voting.

The previous example can provide intuition on the effect of the voting equilibrium over the welfare resulting from regulation. When the median voter is a non-activist (which occurs when $0 \leq \alpha<\frac{1}{2}$ ), the resulting minimal standard will be too low from a social point of view. In such a case, does more activism among consumers/voters imply higher welfare? For a given level of regulation consumers in general benefit from more activism. However, when regulation is endogenous to the voting decision, activist consumers might be worse off after an increase in activism.

To see this, take $\alpha<1 / 2$ (which means that the median voter is non-activist), and consider a change in the preferences of a small group of size $\gamma$ of "non-activists" consumers that become "activist" consumers with $\theta=1$. Assume this group is sufficiently small so that the median voter remains non-activist; that is, $0<\alpha+\gamma<\frac{1}{2}$. Then, this increase in the number of activists will reduce the standard from $x^{*}(1-\alpha)$ to $x^{*}(1-\alpha-\gamma)$. This change in the minimal standard implies that: (i) the welfare of non-activist consumers will obviously increase by a revealed preference argument: they prefer to enjoy a cheaper good even if that increases the aggregate externality; (ii) those consumers that were already activists in the first place might be worse off since they will not change their consumption decision, yet they might face a higher externality; and (iii) more surprisingly, the group of new activists (that previously were nonactivists) may also obtain a lower utility. In this latter case, however, since their preferences have changed, in order to compare both results we need to define a welfare ordering that allows us to compare allocations with ex-ante as well as with ex-post preferences. Thus, we consider that the consumer's welfare unambiguously increases if and only if under the new allocation 
utility increases with respect to ex-ante and ex-post preferences. ${ }^{12}$

Given this restrictive partial order, we can see that the welfare of this group of new activists may well be lower than before. Consider the extreme case where $\alpha=0$. Then, before the change of preferences, all consumers bought the good produced with the socially efficient technology $x=1$, given that the standard was $\bar{x}^{*}(1)=1$. With the change in preferences, the new activists will choose to consume the same socially efficient good but the level of externality will rise due to the lower standard $x^{*}(1-\gamma)$. Similarly, by definition, with the new allocation they would be worse off under the original preferences given that the initial solution coincided with the first best and all consumers were alike.

\section{Extensions}

We now examine the robustness of the results to three different variations of the model. First, we study the implications of a cost of enacting a regulation and show that the same distortions are likely to arise. Second, we show that the distortions we analyze are not an artifact of the use of standards and they also appear with other mechanisms such as pollution taxes. Finally, we introduce a related model in which the market is not covered in the first best, and we show that this might be an additional force towards a lower standard.

\subsection{Cost of Regulation}

Throughout the paper we have assumed that enacting a regulation has no cost. In practice, though, regulation is costly and in this section we show that, in fact, the crowding out of formal regulation by increasing activism is reinforced when regulation has a cost, $K>0$, evenly spread among all consumers. Not surprisingly, the median voter will be willing to regulate to the extent that the cost of regulation is lower than a certain threshold, $\bar{K}$. In the next proposition we show that a distribution with more activists where the median voter remains unchanged is less likely to enact a regulation.

Proposition 3 Let $F(\theta, s)$ be a family of distributions differentiable in $s$ with the same median

\footnotetext{
${ }^{12}$ This welfare ordering has been used in other contexts in papers such as Benhabib and Bisin (2002).
} 


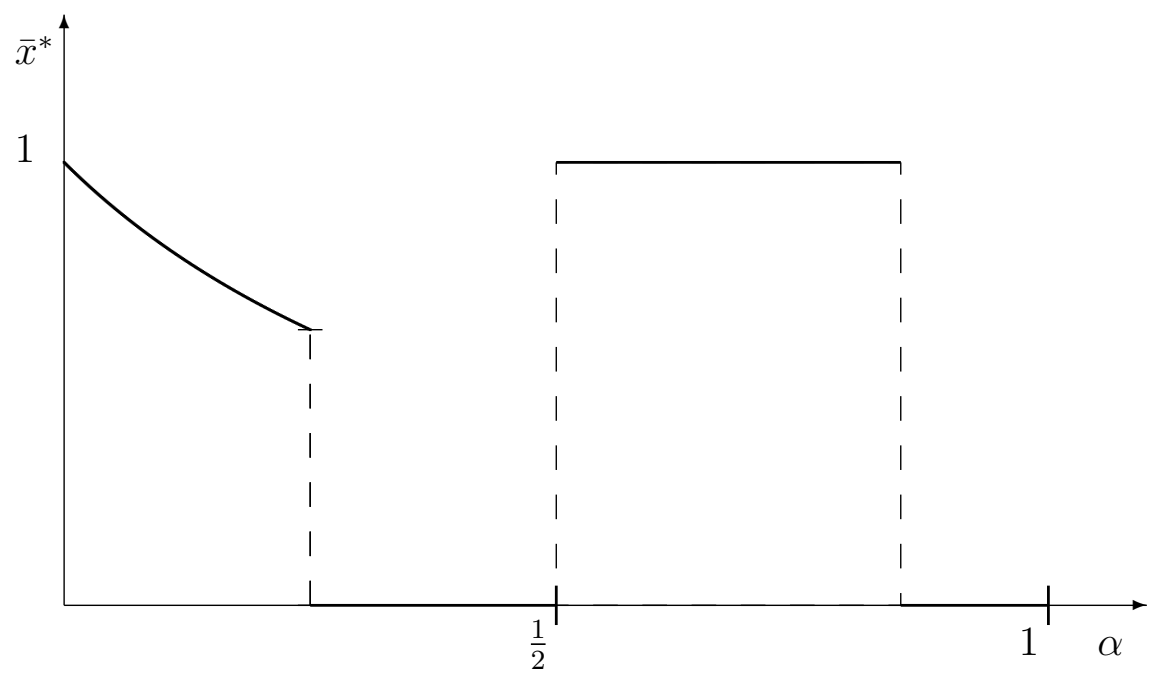

Figure 2: The standard chosen by the median voter when there is a cost of regulation.

such that if $s>s^{\prime}$ then $F(\theta, s) \leq F\left(\theta, s^{\prime}\right)$. That is, distributions are ordered according to the first order stochastic sense. Then, the threshold value for which the median voter regulates, $\bar{K}(s)$ is decreasing in $s$.

The intuition for the result is that the median voter is less interested to regulate when society becomes more conscious, since the more activist consumers there are, the smaller is the gain from setting a standard. Hence, along the same lines of the results in the previous section, an increase in the activism may lead to an increase in the equilibrium level of the externality because the median voter decides not to regulate to avoid the cost. A caveat of the previous result, though, is that a counteracting force may arise if the median voter increases after the change in the distribution. In this case, a more activist median voter might be interested in a more stringent regulation.

The binomial distribution example provides an illustration of the effect of considering the (fixed) cost of regulation. Figure 2 shows that when the proportion of activists increases and the median voter remains constant at either $\theta=0$ or $\theta=1$, regulation is less likely to occur. 
Finally, notice that under a positive cost of regulation, the decision of the median voter and the first best are not likely to coincide. While in the first best we compare the cost of the regulation with the average utility gain from this regulation, the median voter compares his own benefit with his share of the cost of the regulation.

\subsection{Voting on Pollution taxes}

The main point of the paper concerns the opportunistic behavior that non-activist voters might exert over activist consumers through setting a low standard at the expense of a higher externality. One may wonder whether the result is specific of standards or it may apply to other regulatory mechanisms. Here, we show that this result applies to the most commonly studied remedy to the existence of externalities, pollution taxes. In particular, we show that while the first best can be supported with taxes, the majority voting solution on the magnitude of a tax may also be inefficient, leading to a higher than optimal overall externality. However, we also show that this mechanism provides additional interesting trade-offs, caused by the fact that pollution taxes apply to all consumers (as opposed to the case of a minimal standard, where activist consumers were not affected by a low standard), and also by the assumption that taxes are rebated back to consumers. As we will see, both factors diminish, but do not eliminate, the extent of the free-riding problem.

In particular, suppose that, as an alternative scheme, a tax $\tau$ is enacted to penalize each unit of externality beyond the optimal level $b(1)=0$. In the second stage of the game, a consumer of type $\theta$ will now choose the technology $x$ of the good he consumes according to

$$
\max _{x} v-c(x)-(\theta+\tau) b(x) .
$$

Hence, a $\operatorname{tax} \tau>0$ means that a consumer of type $\theta$ will choose a technology as if in the previous scenario he were of type $\min \{\theta+\tau, 1\}$. With some abuse of notation, we denote the consumer's optimal choice as

$$
\hat{x}(\theta+\tau)=\min \left\{x^{*}(\theta+\tau), 1\right\} .
$$

Trivially, the first best can be implemented with a $\operatorname{tax} \tau=1$, which implies that all consumers behave as if they were of type $\theta=1$. 
In the first stage of the game, each voter maximizes his utility by choosing the tax rate that solves

$$
\max _{\tau} v-c(\hat{x}(\theta+\tau))-(\theta+\tau) b(\hat{x}(\theta+\tau))-\int_{0}^{1-\tau} b(\hat{x}(s+\tau)) d F(s)+T,
$$

where $T$ corresponds to the taxes collected, rebated back to consumers as lumpsum payments. That is, consumers receive a payment corresponding to the average tax collected from all consumers,

$$
T=\int_{0}^{1} \tau b(\hat{x}(s+\tau)) d F(s) .
$$

It is easy to verify that a counterpart of the single-crossing condition stated earlier also holds in this case. Therefore, according to Gans and Smart (1996), majority voting results in the preferred tax of the median voter. Then, the median voter maximization problem can be rewritten as

$$
\max _{\tau} v-c(\hat{x}(\tilde{\theta}+\tau))-(\tilde{\theta}+\tau) b(\hat{x}(\tilde{\theta}+\tau))-(1-\tau) \int_{0}^{1-\tau} b(\hat{x}(s+\tau)) d F(s) .
$$

Notice that pollution taxes have two main differences with respect to the scenario where a minimal standard was set. First, while taxation also precludes inefficient technologies (those with $x<\tau$ ), it applies uniformly to all consumers that purchase a good that uses technologies worse than $x=1$. Thus, taxes have a different effect than a minimal standard, which only applies to the consumption decision of non-activists with a low $\theta$. Activist consumers with a high $\theta$ are not affected when a low minimal standard is set. And second, consumers that generate externalities above the average make a net negative transfer to the rest of consumers through the taxes rebated. As a consequence, a non-activist median voter can reduce this net transfer by either choosing a very small tax, at the cost of a high externality, or else by choosing a high tax that provides large incentives to choose a low level of externality, approaching the first best.

Start with the case where all consumers are identical. Then, regardless of their equal degree of activism, no redistribution would occur through taxation and, as a result, the problem would be equivalent to the choice of the optimal standard studied earlier, and the socially optimal 
tax would be chosen. ${ }^{13}$ However, when the distribution of the type $\theta$ of consumers becomes very polarized, a lower than optimal tax is likely to arise. As an illustration consider again the binomial example studied earlier.

Example 1 Suppose that $F(\theta)$ is a binomial distribution with $\theta=1$ with probability $\alpha$ and $\theta=0$ with probability $1-\alpha$. Also suppose that $c(x)=x$ and $b(x)=\beta(1-x)$ where $1<\beta<\frac{1}{1-\alpha}$. It is immediate that $x^{*}(1)=1$ and

$$
x^{*}(0)=\left\{\begin{array}{lc}
1 & \text { if } \tau \beta>1 \\
0 & \text { otherwise }
\end{array}\right.
$$

If the median voter is non-activist - that is, $\alpha<1 / 2$ - the utility of choosing $\tau=1$ and suffering no externality is $v-c(1)=v-1$. However, under the previous parameter restrictions, the utility of choosing $\tau=0, v-c(0)-(1-\alpha) \beta$, is larger.

As opposed to the case of a minimal standard, additional conditions on $c(x)$ and $b(x)$ are necessary for a lower than socially optimal tax to arise. ${ }^{14}$ This is the case because the socially optimal level of externality is more likely to be implemented using taxes. Compared to the case of the minimal standard where a median voter could implement a moderate level of externality and still consume a cheap good, the use of taxes induces a more extreme choice. A moderate tax rate implies a high transfer to activist consumers due to a typical Laffer Curve argument. As a consequence, this tougher decision between a very low tax and a high externality and the socially efficient outcome makes free-riding less likely.

Finally, notice that a non-activist median voter with the possibility of choosing between a minimal standard or a pollution tax is likely to choose the former. The reason is that a standard is a way to limit the transfer to activist consumers. In other words, in some cases a median

${ }^{13}$ The problem of the median/representative voter becomes

$$
\max _{\tau} v-c(\hat{x}(\tilde{\theta}+\tau))-\tilde{\theta} b(\hat{x}(\tilde{\theta}+\tau)),
$$

where by choosing $\tau=x^{*-1}(\bar{x})-\theta$ we implement the standard $\bar{x}$.

${ }^{14}$ For simplicity and contrary to the rest of the paper, the example we provide assumes that $b(x)$ is weakly convex in $x$. As a result consumer decisions $x^{*}$ correspond to corner solutions, simplifying calculations. Strictly convex approximations of this function will certainly result in the same distortions. 
voter would choose a socially inefficient low standard, but when choosing only a pollution tax, $\tau=1$ would maximize his utility. Because the outcome corresponding to $\tau=1$ was feasible by setting a standard of 1 , a simple revealed preference argument implies that the use of a minimal standard will be preferred by a non-activist voter to the use of pollution taxes as a regulatory device.

\subsection{Endogenous Market Size}

As a last extension of the base model, we relax one of the assumptions that we have maintained throught the paper, namely, that all consumers purchase the good regardless of the standard they are subject to. So far, we have shown that the distortion in the standard chosen by the median voter originated from the dispersion in the activism of consumers. Interestingly, we now illustrate how the results can be reinforced if consumers are heterogeneous in their valuation for the good $v$. To do so, and in order to simplify the exposition we assume that all consumers have the same level of activism $\theta$. The consumer valuation $v$ is drawn from a distribution $G(v)$ with density $g(v)$. In this case, consumer's participation (that is, their decision to buy the good) is endogenous to the technologies allowed.

The social welfare problem amounts to choosing the smallest valuation for the good, $\underline{v}^{s}$, for which consumption is allowed, together with the technology that each consumer should use, $x^{s}(v)$. That is,

$$
\max _{\underline{v}^{s}, x^{s}(v)} \int_{\underline{v}^{s}}\left(v-c\left(x^{s}(v)\right)-\theta b\left(x^{s}(v)\right)\right) g(v) d v-\int_{\underline{v}^{s}} b\left(x^{s}(v)\right) g(v) d v,
$$

where first order conditions imply that either no consumption should occur (if, for example, the support of $v$ is too low) or else $\underline{v}^{s}=c(1)$ and $x^{s}=1$ for all $v$. This result is immediate from the fact that, when not all consumers buy the good, the optimal standard should take into account that the externality is suffered by all consumers even though only some purchase the good. Because only the cleanest technology is allowed, optimality implies that the marginal consumer should obtain utility equal to the total cost of producing the good. ${ }^{15}$

\footnotetext{
${ }^{15}$ If $b(1)$ were strictly positive, optimality would imply that $\underline{v}^{s}=c(1)+(\theta+1) b(1)$ since the marginal consumer must add utility that compensates the private cost of the externality and the social cost that it generates to everybody.
} 
Absent any regulation all consumers maximize their utility using the same technology, $x^{*}(\theta)$. As a result, the externality will be above the social optimum due to both the fact that an inefficient technology is used and that overconsumption occurs. The consumer with the lowest valuation that buys the good is defined by

$$
\underline{v}^{c}=c\left(x^{*}(\theta)\right)+\theta b\left(x^{*}(\theta)\right)<\underline{v}^{s} .
$$

Consider now the case in which a meaningful minimal standard $\bar{x}>x^{*}(\theta)$ is implemented as the outcome of a voting decision. For a given standard $\bar{x}$, the consumer with the lowest willingness to pay that will buy corresponds to

$$
\underline{v}^{*}(\bar{x})=c(\bar{x})+\theta b(\bar{x}) .
$$

This function is strictly increasing in $\bar{x}$ for all $\bar{x}>x^{*}(\theta)$. As a result, a voter with valuation $v$ prefers a standard that maximizes

$$
\max _{\bar{x}}(v-c(\bar{x})-\theta b(\bar{x})) I\left(v \geq \underline{v}^{*}(\bar{x})\right)-\left(1-G\left(\underline{v}^{*}(\bar{x})\right)\right) b(\bar{x}),
$$

where $I\left(v \geq \underline{v}^{*}(\bar{x})\right)$ equals 1 when $v \geq \underline{v}^{*}(\bar{x})$, and 0 otherwise.

Notice that if the voter $v$ does not purchase the good, he will choose the socially optimal standard in order to minimize the externality he suffers. Similarly, contingent on purchasing the good, any voter $v$ will choose the same standard. Hence, this argument provides a simple single-crossing condition that implies that a voter with a higher valuation prefers a weakly lower standard. As before, the standard chosen as a result of the voting decision, $\tilde{v}$, corresponds to the preferred standard of the median voter. We characterize this result in the next proposition that turns out to be a counterpart of Proposition 1.

Proposition 4 Majority voting determines a standard that is either the socially optimal level $\bar{x}^{*}=1$, or $x^{*}\left(\theta_{2}\right)<1$, where

$$
\theta_{2}=\theta+H\left(\theta_{2}\right),
$$

with

$$
H\left(\theta_{2}\right) \equiv \frac{1-G\left(\underline{v}^{*}\left(x^{*}\left(\theta_{2}\right)\right)\right)}{1-g\left(\underline{v}^{*}\left(x^{*}\left(\theta_{2}\right)\right)\right) b\left(x^{*}\left(\theta_{2}\right)\right)}>0 .
$$


From equation (5) we can observe that the standard implemented does not depend on the specific willingness to pay of the median voter, but rather on whether he purchases the good or not. We conclude this section by illustrating the previous result with an example similar to the one used when the heterogeneity among voters was due to the difference in their degree of activism.

Example 2 Let $G(v)$ be a two-point distribution with $v=0$ with probability $\alpha$ and $v=1$ with probability $1-\alpha$, for $\bar{v}$ sufficiently high to guarantee that high valuation consumers always buy the good. Assume all consumers are non-activist $\theta=0$. In a similar way as in the rest of the paper, when $\alpha>1 / 2$, the median voter does not buy the good and hence he is only concerned about minimizing the externality, choosing $\bar{x}^{*}=1$.

If $\alpha<1 / 2$ the median voter buys the good. Adapting equation (4) to a discrete distribution of valuations we obtain that the median voter solves

$$
\max _{\bar{x}} \tilde{v}-c(\bar{x})-(1-\alpha) b(\bar{x})
$$

so that the standard that maximizes utility for the median voter is $x^{*}(1-\alpha)$. As a function of $\alpha$ the optimal standard turns out to be identical to the one depicted in Figure 1. Moreover, for $\theta>0$ the standard would correspond to $x^{*}\left(\theta_{2}\right)$, where $\theta_{2}=\min \{1-\alpha+\theta, 1\}$, and in the picture it would be represented as a vertical shift of the curve.

\section{Concluding Remarks}

In this paper we provide a model in which the level of activism of consumers drives the production decision of competitive firms. We assume that the more activist consumers are, the lower is their willingness to pay for goods produced with technologies that create larger externalities. As a consequence, and as intuition would suggest, more activism induces firms to choose technologies closer to the socially optimal ones. This simple mechanism is only half of the story, since these private politics take place in an environment where the firms' decisions can also be affected by the regulatory framework. Private politics co-exist with formal regulation. 
This formal regulation is established by activist and non-activist consumers alike, as a result of a political decision process (public politics). To the extent that voters take into account the private politics subsequent to the established regulation, surprising results might arise. If all voters are non-activists, they are aware that private politics doesn't play any role in controlling the externality and they commit themselves to a strict regulatory framework. However, when a majority of voters are non-activist in an environment with highly activist consumers, they can take advantage of these private politics. They might choose a loose regulatory framework that allows them to choose goods produced with technologies with a low private cost (and price) and free-ride over the conscious behavior of activist consumers to limit the externality. Hence, contrary to what the intuition might suggest, taking into account the endogeneity of the regulation might lead to the result that societies with more activists suffer a higher level of externality.

Our analysis also contributes to the ongoing debate regarding the implications of Corporate Social Responsibility (CSR) by cautioning against the present trend towards a higher reliance on private politics (that is, the interaction between CSR and activism) and against formal regulation. The potential crowding out of strict regulation by looser self-regulation by firms might result in activists carrying alone the burden of a conscious consumption (which increases social welfare), whereas non-activists would enjoy the benefits of both a less regulated environment and the conscious consumption of activists, without incurring in its costs. As a consequence, an increasing reliance on the social responsibility of firms rather than on regulatory guidelines might be overall welfare diminishing.

The objective of the paper was to show that the complex interaction between private and public politics may yield unexpected outcomes. To make this point, we have chosen a very simple framework that makes clear the possible conflict. We now discuss the role of some alternative assumptions.

First, we have limited the extent of activism so that conscious consumers cannot internalize more than their share of the total externality. Moreover, we do not include inefficiently clean technologies. Relaxing both assumptions would make it easier to show that increasing activism 
could lead to inefficient outcomes. However, the result would arise from the complementarity between private politics and public politics under the control of activist consumers that would choose inefficiently high standards. This is in contrast with our model where inefficiency arises from the control of public politics by non-activists.

Second, we have assumed perfect competition in the supply side. This assumption allows us to ignore the debate over the preferences of the firm regarding their degree of social responsability. Because our results rely on demand-side behavior, we are confident that imperfect competition would yield similar outcomes as long as consumers can capture some of the rents from their purchase. If consumers faced a monopolist that could perfectly discriminate among them, the free-riding equilibrium would not occur. Consumers would not be able to benefit from choosing a lower standard and consuming a cheaper good.

Finally, the model abstracts from several interesting dimensions in the debate on the role activism that might lead to further research. In particular, the one we consider most important is extending the analysis to multidimensional voting decisions where, for example, environmental decisions are voted alongside with redistributional issues. 


\section{A Proofs}

\section{Proof of Lemma 1}

For a consumer of type $\theta$ that consumes a good $x$, a marginal increase in $x$ increases the utility of the consumer in $-c^{\prime}(x)-\theta b^{\prime}(x)$ and reduces the externality in $-b^{\prime}(x)$. Given that $c^{\prime}(x)+b^{\prime}(x)$ is negative,

$$
-c^{\prime}(x)-b^{\prime}(x)-\theta b^{\prime}(x)>0
$$

which results in the corner solution $x^{s}=1$.

\section{Proof of Lemma 2}

Immediate from the definition of $B=\int_{0}^{1} b(\hat{x}(\theta, \bar{x})) d F(\theta), \hat{x}$ weakly increasing in $\theta$ and $b^{\prime}<0$.

\section{Proof of Lemma 3}

We can simply show that voter's utility is larger for $\bar{x}=x^{*}(\theta)$ than for any lower standard $\tilde{x}$. In particular, from (2) we can compute the difference in utility between the two standards as

$$
-\int_{\theta^{-1}(\tilde{x})}^{\theta}\left(b(\bar{x})-b\left(x^{*}(s)\right)\right) d F(s)>0
$$

which proves the result.

\section{Proof of Lemma 4}

It is immediate to observe that

$$
\frac{\partial^{2} U}{\partial \bar{x} \partial \theta}=-b^{\prime}(\bar{x})>0
$$

so that $U$ has increasing differences. The single-crossing condition is a weaker requirement implied by this condition.

\section{Proof of Proposition 1}

The maximum of $U(\bar{x}, \tilde{\theta})$ is characterized by the first order condition

$$
-c^{\prime}(\bar{x})-\tilde{\theta} b^{\prime}(\bar{x})-b^{\prime}(\bar{x}) F\left(\theta^{-1}(\bar{x})\right) \geq 0
$$


with equality if $\bar{x}<1$. Using the definition of $\theta^{-1}(\bar{x})$, equation (1), and by dividing by $b^{\prime}\left(\bar{x}^{*}\right)$, the previous expression can be rewritten for interior values of the optimal standard $\bar{x}^{*}$ as

$$
\tilde{\theta}=\theta^{-1}\left(\bar{x}^{*}\right)-F\left(\theta^{-1}\left(\bar{x}^{*}\right)\right)
$$

Defining $\theta_{1} \equiv \theta^{-1}\left(\bar{x}^{*}\right)$ we obtain the desired result. Notice that $\bar{x}=1$ will always be a local maximum since the first order condition evaluated at that point is greater than 0 .

\section{Proof of Proposition 2}

See section 3.1.

\section{Proof of Proposition 3}

The median voter will regulate if

$$
U\left(\bar{x}^{*}, \tilde{\theta}\right)-U(0, \tilde{\theta}) \geq K
$$

This expression corresponds to

$\bar{K}(s)=U\left(\bar{x}^{*}, \tilde{\theta}\right)-U(0, \tilde{\theta})=c\left(x^{*}(\tilde{\theta})\right)+\tilde{\theta} b\left(x^{*}(\tilde{\theta})\right)-c\left(\bar{x}^{*}\right)-\tilde{\theta} b\left(\bar{x}^{*}\right)-\int_{0}^{\theta^{-1}\left(\bar{x}^{*}\right)}\left(b\left(\bar{x}^{*}\right)-b\left(x^{*}(z)\right)\right) d F(z, s)$.

Taking the derivative with respect to $s$,

$$
\frac{d \bar{K}}{d s}=\frac{\partial \bar{K}}{\partial \bar{x}^{*}} \frac{\partial \bar{x}^{*}}{\partial s}+\frac{\partial \bar{K}}{\partial s}=\frac{\partial}{\partial s}\left(-\int_{0}^{\theta^{-1}\left(\bar{x}^{*}\right)}\left(b\left(\bar{x}^{*}\right)-b\left(x^{*}(z)\right)\right) d F(z, s)\right)<0,
$$

where the envelop condition allows us to show that $\frac{\partial \bar{K}}{\partial \bar{x}^{*}}=0$ and the last expression originates from $b\left(\bar{x}^{*}\right)-b\left(x^{*}(z)\right)$ being increasing in $z$ and the definition of first order stochastic dominance.

\section{Proof of Proposition 4}

We need to consider two separate problems. When the median voter does not buy the good, it is immediate that his objective function corresponds to the minimization of the externality. In other words, $\bar{x}=1$.

When the median voter buy the good, the first order condition corresponding to problem (4) is

$$
\left.\left.\left(1-g\left(\underline{v}^{*}(\bar{x})\right)\right) b(\bar{x})\right)\left(-c^{\prime}(\bar{x})-\theta b^{\prime}(\bar{x})\right)-\left(1-G\left(\underline{v}^{*}(\bar{x})\right)\right)\right) b^{\prime}(\bar{x})=0 .
$$


Denote $\theta_{2}$ the type for which $\bar{x}=x^{*}\left(\theta_{2}\right)$. Replacing $\frac{c^{\prime}(\bar{x})}{b^{\prime}(\bar{x})}$ evaluated at $\theta_{2}$ from equation (1) and rearranging we obtain the desired result. A necessary condition for the previous equation to hold is that $\left.1-g\left(\underline{v}^{*}(\bar{x})\right)\right) b(\bar{x})>0$ so that $H\left(\theta_{2}\right)>0$ and $\theta_{2}>\theta$. 


\section{References}

Andreoni, JAmes, "Philanthropy," in Jean Mercier Ythier L.-A. Gerard-Varet, SergeChristophe Kolm, ed., Handbook of Giving, Reciprocity and Altruism, Handbooks in Economics, Elsevier, 2004 .

Bargnoli, Mark and Susan G. Watts, "Selling to Socially Responsible Consumers: Competition and the Private Provision of Public Goods," Journal of Economics and Management Strategy, 2003, 12(3), pp. 419-445.

Baron, David, "Private Politics, Corporate Social Responsability and Integrated Strategy," Journal of Economics and Management Strategy, 2001, 10(1), pp. 7-45.

—, "Private Politics," Journal of Economics and Management Strategy, 2003, 12(1), pp. 31-66.

Benhabib, Jess and Alberto Bisin, "Advertising, Mass Consumption and Capitalism," 2002.

Carroll, Archie B., "A Three-Dimensional Conceptual Model of Social Performance," Academy of Management Review, 1979, 4, pp. 497-505.

Ciorcirlan, C. and Bruce Yandle, "The Political Economy of Green Taxation in OECD Countries," European Journal of Law and Economics, 2003, 15, pp. 203-218.

Elliott, E., B.J. Seldon And J.L. Regens, "Political and Economic Determinants of Individuals' Support for Environmental Spending," Journal of Environmental Management, 1997, 51, pp. 15-27.

Feddersen, Timothy J. and Thomas W. Gilligan, "Saints and Markets: Activists and the Supply of Credence Goods," Journal of Economics and Management Strategy, 2001, 10(1), pp. 149-171.

Gans, Joshua S. And Michael Smart, "Majority Voting with Single-Crossing Preferences," Journal of Public Economics, 1996, 59, pp. 219-238. 
Innes, RoBert, "A Theory of Consumer Boycotts under Symmetric Information and Imperfect Competition," 2005.

Kahn, Matthew E. And John G. Matsusaka, "Demand for Environmental Goods: Evidence from Voting Patterns on California Initiatives," Journal of Law ES Economics, 1997, 40(1), pp. 137-73.

Marsiliani, Laura and Thomas Renstrom, "On Income Inequality and Green Preferences," 2002, discussion paper CEPR 3677, and W. Allen Wallis Institute of Political Economy, University of Rochester, Working Paper no. 30/2002.

McWilliams, A. And D. Siegel, "Corporate Social Responsability: A Theory of the Firm Perspective," Academy of Management Review, 2001, 26(1), pp. 117-127.

Mohr, Lois A., Deborah J. Webb and Katherine Harris, "Do Consumers Expect Companies to Be Socially Responsible? The Impact of Corporate Social Responsability on Buying Behavior," Journal of Consumer Affairs, 2001, 35(1), pp. 45-72.

Murray, K. And C. Volgel, "Using a Hierarchy of Effects Approach to Gauge the Effectiveness of Corporate Social Responsability to Generate Goodwill Toward the Firm: Financial versus Nonfinancial Impacts," Journal of Business Research, 1997, 38. 